\title{
Efficiency and Stability of Capacitance of the PV System
}

\author{
Guozhong Zhou ${ }^{1, a}$, Yan Cui ${ }^{2, b}$ \\ ${ }^{1}$ Department of Electronic Engineering, Shantou University, Shantou ,515063, China \\ ${ }^{2}$ Department of Electronic Engineering, Shantou University, Shantou ,515063, China \\ a136158959@qq.com, bycui@stu.edu.cn
}

Keywords: Capacitor. Improve the Efficiency of Independent Photovoltaic Power Generation System. Stability

Abstract: The output of the PV array capacitance change influence the output efficiency of photovoltaic power generation system. The study of the circuit is a stand-alone photovoltaic power generation system, theoretical analysis and simulation results can be well combined with the PV array output suggests adding a suitable transition period can increase capacitance PV system and reduce ripple.

\section{Introduction}

PV system circuit in practical applications, there are many problems, such as the output power is unstable or stable slow, forthermore, ripple is relatively large. Photovoltaic power generation systems need to solve these issues, photovoltaic systems will produce faster output power stability and small ripple.The system must have the effective of filtering and can also reduce the time to reach stable output. Capacitance is more suitable to solve this problem, the key is to choose the appropriate capacitance value.

\section{Pv Power System Circuit based on Multisim}

In this paper, the independent photovoltaic of DC-DC boost circuit,which analog the output of PV panels and takes paralleling multiple PV arrays. The capacitance is added to the output power which its fairly constant voltage source (battery). Since the voltage across the capacitor can not change suddenly, only the spot-effect transistor is off when the voltage photovoltaic power to charge. Field effect tube is open when the capacitor discharges. In addition, Capacitance also hava filtering effective. System circuit diagram is shown in Fig. 1.

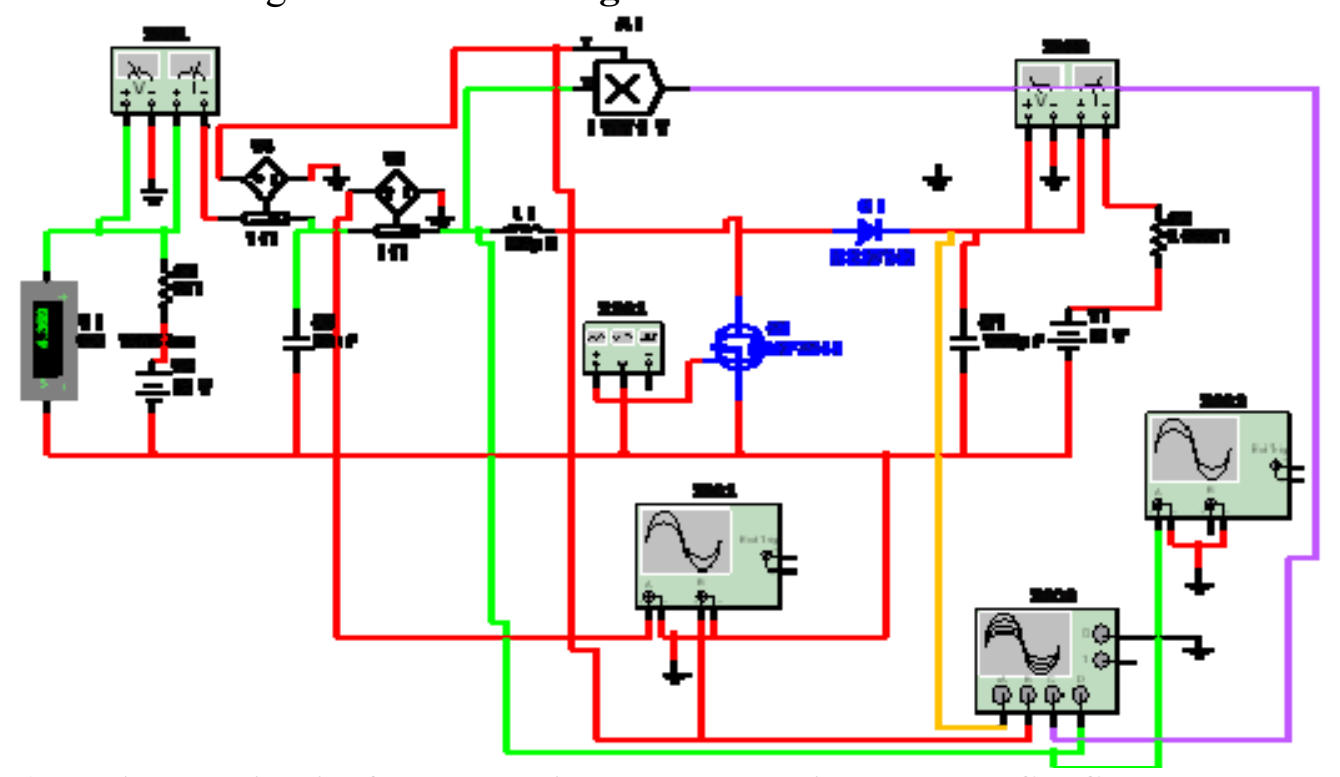

Fig. 1 Equivalent circuit of photovoltaic power generation system DC-DC power conversion 


\section{Capacitive Technology and Simulation Analysis of Photovoltaic Power Generation System}

\section{Setting PV System Parameters in Various Components}

In order to study the efficiency and stability of photovoltaic power generation system with the addition of capacitor, the photovoltaic array 1 equivalent resistance of a power supply voltage when selecting $10 \mathrm{~V}$, internal resistance $5 \Omega$,making further to find the largest PV system power point after reaching the maximum power point to stabilize. However, every component parameter setting of circuit design is critical.Determine the Fig. 1 parameters of inductance L1 and capacitor C1 parameters is particularly important, the design of the switch is multisim comes IRFZ24N, The initial duty cycle is $50 \%$, frequency of $20 \mathrm{kHz}$, select the inductor ripple current value principle is no more than $10 \%$ to $20 \%$ of the peak , after the simulation determine the post-simulation is $20 \%$, and the inductor ripple current inductor satisfies Eq. 1:

$$
\Delta \mathrm{i}=\frac{U_{I N}}{L} D T
$$

Where is the open-circuit voltage of the PV array is $10 \mathrm{~V}, \mathrm{D}$ and $\mathrm{T}$ are the duty cycle and cycle of the switching signal, $\mathrm{L}$ is the inductance value, MOS tube switching frequency $20 \mathrm{kHz}$, namely $\mathrm{T}=$ $0.05 \mathrm{~ms}$; The relationship between the inductor ripple and current satisfies Eq. 2:

$$
L=\frac{U_{I N}}{0.2 I_{p m}} D T
$$

From (2) formula to calculate the inductance $\mathrm{L}=625 \mathrm{uH}$,final selection of $220 \mathrm{uH}$. Determine the capacitance parameters is realted to DC-DC converter control switch time, DC-DC converter output voltage and input voltage relationship by controlling the switch-off time, this signal which achieved by a PWM control signal. The main principle is to keep the on-off cycle constant, adjust switch on-duration to control the voltage.The Schematic diagram is shown in Fig. 2

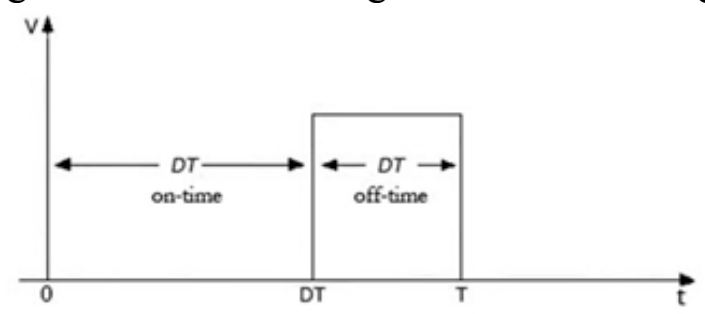

Fig. 2 The PWM's duty cycle is $D$

PWM signals shown in figure 2.1, the period is T. D is the duty cycle of the PWM signal. Representing the amount of charge flowing through the capacitor, only if the MOS switch is in the off state, photovoltaic power supply to the capacitor charge. In the one switching period $\mathrm{T}$ only in off-time filter capacitors have accumulated charge amount, the output ripple voltage may be determined to satisfy Eq. 3:

$$
\Delta U_{o}=\frac{\Delta Q}{C}=\frac{I_{o} \cdot \mathrm{t}_{\text {off }}}{C}=\frac{I_{o} \cdot(1-D)}{C}
$$

In the Eq. 3 formula, is showing off time, represent on time. By Eq. 4 to give:

$$
C=\frac{I_{o} \cdot(1-D)}{0.02 U_{o}}
$$

Duty cycle and switching period were $50 \%$ and $0.05 \mathrm{~ms}$, taken as $2 \%$ of the output voltage . Meanwhile, assuming 100\% conversion efficiency of the circuit, according to the above formula, the input electric current can be obtained corresponding to $2.23 \mathrm{~A}$, the input voltage is $10 \mathrm{~V}$ and the output voltage when the output voltage $12 \mathrm{~V}$,the $=1.67 \mathrm{~A}$. Finally (1.4) determines the output filter capacitor according to the formula, the final selection of $1000 \mathrm{uF}$ after testing simulation. Identified four main parameters of BOOST circuit, we build a DC-DC converter circuit in MULTISIM software, the photovoltaic array assembly is connected at the input of the power supply has been equivalent to contain internal resistance. $12 \mathrm{~V}$ battery output termination. PWM signal generated by the software 
comes MULTISIM pulse excitation source instead of a frequency of $20 \mathrm{kHz}, 50 \%$ duty cycle, high level 5V, low level $0 \mathrm{~V}$.

\section{The Output of PV Modules Added Capacitor Simulation}

As can be seen from the waveform of these Fig. 3 and Fig. $\mathbf{4}$, after the addition of capacitance, played a filter made with reduced output current of photovoltaic power generation system, voltage and power ripple. both figures are relatively stable waveform, DC-DC circuit requires a higher voltage and current stability in engineering practice.
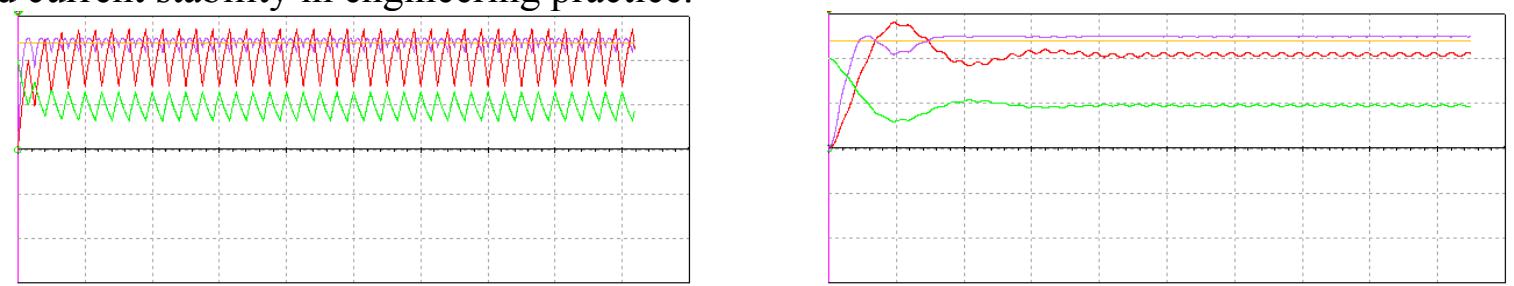

Fig. 3 Simulation results with che capacitor XSC3 Fig. 4 Simulation results without che capacitor XSC3

How much capacitance values to choose which you can make stable output side capacitor voltage waveform, the input electric current waveform, stable output waveform smooth?Red is a electric current waveform, the waveform purple is power waveform, green waveform is a source.

Through simulation analysis, the mathematical model boost circuit, you can calculate the value of $\mathrm{C} 3$ in $\mathrm{uF}$ level, represents the inductor electric current, output electric current of the PV array, where the choice between $1 \sim 1000 \mathrm{uF}$ change, PV system output electric current, voltage, power waveform more stable is an ideal output waveform, for finding the best power point can be increased and stable power output waveform is the key to selecting the capacitance values. The simulation result data obtained is shown in Table 1

Table 1 Power meter in different C3[uF] value

\begin{tabular}{|l|c|c|c|c|c|c|c|c|c|c|}
\hline C3[uF] & 10 & 20 & 30 & 40 & 50 & 60 & 70 & 80 & 90 & 100 \\
\hline InPower[w] & 4.706 & 4.710 & 4.711 & 4.711 & 4.711 & 4.711 & 4.711 & 4.711 & 4.711 & 4.711 \\
\hline OutPower[w] & 4.540 & 4.544 & 4.545 & 4.545 & 4.545 & 4.545 & 4.545 & 4.545 & 4.545 & 4.545 \\
\hline OutP/InP & 0.9647 & 0.9647 & 0.9647 & 09647 & 0.9647 & 0.9647 & 0.9647 & 0.9647 & 0.9647 & 0.9647 \\
\hline
\end{tabular}

From the analysis of the data in Table 1 at 20-30uF power has reached the maximum, in order to further explore the maximum power point, during this period looking for the maximum power point, the simulation result data obtained are shown in Table 2.

Table 2 Power meter in different C3 value

\begin{tabular}{|l|l|l|l|l|l|l|l|l|l|l|}
\hline C3[uF] & 21 & 22 & 23 & 24 & 25 & 26 & 27 & 28 & 29 & 30 \\
\hline InPower[w] & 4.710 & 4.710 & 4.710 & 4.710 & 4.711 & 4.710 & 4.710 & 4.711 & 4.711 & 4.711 \\
\hline OutPower[w] & 4.544 & 4.544 & 4.545 & 4.545 & 4.545 & 4.545 & 4.545 & 4.545 & 4.545 & 4.545 \\
\hline OutP/InP & 0.9647 & 0.9647 & 0.9649 & 0.9649 & 0.9647 & 0.9647 & 0.9647 & 0.9647 & 0.9647 & 0.9647 \\
\hline
\end{tabular}

From the above two tables it shows that after adding capacitance, optimal capacitance value is 23,24 uF. In $23 \mathrm{uF}$ capacitance and added capacitance data not added as shown in Table 3: From the data in Table 3, with and without added capacitance capacitor contrast, than the maximum power increase $0.1 \%$, although the increase is less, capacitance was added to improve the power ratio of the does have effect. 
Table 3 Comparison of the maximum power of a capacitor ( $\mathrm{Y}$ or $\mathrm{N})$

\begin{tabular}{|l|c|c|}
\hline C3[uF] & Y & N \\
\hline InPower[w] & 4.710 & 4.513 \\
\hline OutPower[w] & 4.545 & 4.353 \\
\hline OutP/InP & 0.9649 & 0.9639 \\
\hline
\end{tabular}

\section{Conclusions}

This article is based on the output of photovoltaic systems added capacitance by adjusting the capacitance value of the efficiency of photovoltaic power generation system, thereby selecting the best capacitor values. Simulation results show that at the switching frequency, duty cycle of certain conditions, the capacitance value of the adjustment can improve the output power of the PV system and achieve the transition time photovoltaic system. Overall system performance has improved to some extent, with a good value.

\section{Acknowledgements}

Grateful acknowledgement is made to my supervisor Mr. Cui Yan who gave me considerable help by means of suggestion, comments and criticism. His encouragement and unwavering support has sustained me through frustration and depression. Without his pushing me ahead, the completion of this thesis would be impossible. In addition, I deeply appreciate the contribution to this thesis made in various ways by my friends and classmates.

\section{References}

[1] Cong ark.Nanjing Institute of Information Engineering, 2013.

[2] He Junqiang, research Liu Jinbo sliding mode based photovoltaic power generation system MPPT algorithm Shandong University, 2012.

[3] Salish Maharjan, Jimmy C. H. Peng and Weidong Xiao, Improved Deterministic Real-Time Estimation of Maximum Power Point in Photovoltaic Power Systems. Department of Electrical Engineering and Computer Science Masdar Institute of Science andTechnology.Abu Dhabi, United Arab Emirates,2015.

[4] Liwen, Zhangju Wei, Tian Wei, Zhang Xiaohong: Electronic Information Engineering, Henan University of Science and Technology, 2010.

[5] Than Phu Nguyen.The University of Queensland Department of Computer Science \& Electrical Engineering ,2001.

[6] Yellow Kea ,research photovoltaic system maximum power point tracking algorithm and implementation [D]. Soochow University ,2010. 